\title{
A meta-analysis of the effects of therapeutic hypothermia in adult patients with traumatic brain injury
}

\author{
Hanbing Chen ${ }^{1}$, Fei $\mathrm{Wu}^{2}$, Penglei Yang ${ }^{1}$, Jun Shao ${ }^{3}$, Qihong Chen ${ }^{4^{*}}$ and Ruiqiang Zheng ${ }^{3}$
}

\begin{abstract}
Purpose: Therapeutic hypothermia management remains controversial in patients with traumatic brain injury. We conducted a meta-analysis to evaluate the risks and benefits of therapeutic hypothermia management in patients with traumatic brain injury.

Methods: We searched the Web of Science, PubMed, Embase, Cochrane (Central) and Clinical Trials databases from inception to January 17, 2019. Eligible studies were randomised controlled trials that investigated therapeutic hypothermia management versus normothermia management in patients with traumatic brain injury. We collected the individual data of the patients from each included study. Meta-analyses were performed for 6-month mortality, unfavourable functional outcome and pneumonia morbidity. The risk of bias was evaluated using the Cochrane Risk of Bias tool.
\end{abstract}

Results: Twenty-three trials involving a total of 2796 patients were included. The randomised controlled trials with a high quality show significantly more mortality in the therapeutic hypothermia group [risk ratio (RR) 1.26, 95\% confidence interval (CI) 1.04 to $1.53, p=0.02$ ]. Lower mortality in the therapeutic hypothermia group occurred when therapeutic hypothermia was received within $24 \mathrm{~h}$ (RR $0.83,95 \% \mathrm{Cl} 0.71$ to $0.96, p=0.01$ ), when hypothermia was received for treatment (RR $0.66,95 \% \mathrm{Cl} 0.49$ to $0.88, p=0.006$ ) or when hypothermia was combined with postcraniectomy measures (RR $0.69,95 \% \mathrm{Cl} 0.48$ to $1.00, p=0.05$ ). The risk of unfavourable functional outcome following therapeutic hypothermia management appeared to be significantly reduced (RR $0.78,95 \% \mathrm{Cl} 0.67$ to $0.91, p=0.001$ ). The meta-analysis suggested that there was a significant increase in the risk of pneumonia with therapeutic hypothermia management (RR 1.48, 95\% Cl 1.11 to $1.97, p=0.007$ ).

Conclusions: Our meta-analysis demonstrated that therapeutic hypothermia did not reduce but might increase the mortality rate of patients with traumatic brain injury in some high-quality studies. However, traumatic brain injury patients with elevated intracranial hypertension could benefit from hypothermia in therapeutic management instead of prophylaxis when initiated within $24 \mathrm{~h}$.

Keywords: Therapeutic hypothermia, Normothermia, Traumatic brain injury, Mortality, Meta-analysis

\footnotetext{
*Correspondence: chenqihong00@163.com

${ }^{4}$ Department of Critical Care Medicine, Jiangdu People's Hospital of Yangzhou, Jiangdu People's Hospital Affiliated to Medical College of Yangzhou University, No 9 Dongfanghong Road of Jiangdu District, Yangzhou 225001, Jiangsu, China

Full list of author information is available at the end of the article
}

(c) The Author(s). 2019 Open Access This article is distributed under the terms of the Creative Commons Attribution 4.0 International License (http://creativecommons.org/licenses/by/4.0/), which permits unrestricted use, distribution, and reproduction in any medium, provided you give appropriate credit to the original author(s) and the source, provide a link to the Creative Commons license, and indicate if changes were made. The Creative Commons Public Domain Dedication waiver (http://creativecommons.org/publicdomain/zero/1.0/) applies to the data made available in this article, unless otherwise stated. 


\section{Introduction}

Traumatic brain injury (TBI) is a great challenge to public health; more than 50 million people suffer from TBI every year worldwide [1]. TBI can cause swelling (oedema) in the brain, can increase intracranial hypertension (ICP) and can worsen the injury. Cell death can occur minutes to hours after the injury, and the harmful effects can last for $72 \mathrm{~h}$ or longer [2]. Therapeutic hypothermia $(\mathrm{TH})$ can reduce ICP [3] and, to some extent, play the role of a neuroprotective agent, thereby protecting the function of neurons, improving the prognosis of patients and achieving the goal of reducing mortality [4].

To date, TH in patients with TBI remains controversial. The results of a large number of animal experiments support TH management [5], and numerous studies have shown that $\mathrm{TH}$ can improve neurological outcomes and reduce mortality [6, 7]. However, in recent years, some studies have considered that $\mathrm{TH}$, compared with the control condition, did not ameliorate outcomes among patients with severe TBI $[8,9]$. Moreover, a large multicentre trial showed that $\mathrm{TH}$ played a negative role in the mortality rate and functional outcome [2]. From this, we can see that the $\mathrm{TH}$ strategies remain controversial in patients with TBI.

Systematic reviews have also reported conflicting results [10-12]. A large meta-analysis reported a benefit of $\mathrm{TH}$, but this may be due to the influence of a large number of low-quality studies [12]. However, a recent metaanalysis suggested that $\mathrm{TH}$ could cause more mortality and poor outcomes in high-quality studies [13]. The aim of this meta-analysis is to use RCTs to update the evidence according to when and who administered $\mathrm{TH}$ to patients with TBI by analysing 6-month mortality rates, functional outcome, and pneumonia morbidity.

\section{Methods}

This meta-analysis was performed according to the Preferred Reporting Items for Systematic Reviews and Meta-Analyses: the PRISMA statement [14]. The review was registered with the PROSPERO International prospective register of systematic reviews (registration number CRD42019121207).

\section{Eligibility criteria}

All studies included in our meta-analysis met the following criteria:

1. Type of research: Clinical randomised controlled trial

2. Population: Patients with TBI

3. Intervention: $\mathrm{TH}$ management

4. Control: Normothermia management or fever control
5. Research outcomes:

a) Primary outcomes: 6-month mortality, unfavourable functional outcome [Glasgow Outcome Scale (GOS) score 1-3: 1, death; 2, a vegetative state; 3 , severe disability. Or Glasgow Outcome ScaleExtended (GOS-E) score 1-4: 1, death; 2, vegetative state; 3-4, severe disability]

b) Secondary outcome: Pneumonia morbidity

\section{Search strategy}

We searched the PubMed, Web of Science, Embase, Cochrane (Central) and Clinical Trials databases from inception to January 17, 2019, for studies discussing $\mathrm{TH}$ management in patients with TBI. All of the studies we included were independently screened and read by two authors. By reading the abstracts and topics, we excluded clearly unrelated literature, and by reading the full texts, we included only articles that fully met the requirements. When there was a disagreement about a study, the third author arbitrated discussions until a decision was reached. All of the included studies were limited to English articles that could be retrieved. In addition, we manually reviewed the relevant journals that were available.

\section{Data extraction}

Data were collected using an author-created information extraction form. The two authors independently extracted the required content by screening the literature. When there was a dispute about a study, the two authors reached a consensus through discussion. If no consensus could be reached, the third author arbitrated until a final decision was reached. The data extracted from each trial included the following: first author, publication date, sample content, inclusion criteria, exclusion criteria, Glasgow Coma Score (GCS) on admission, outcome data for the GOS or GOSE, induction time, target temperature of the hypothermia group, hypothermia duration, rewarming rate, follow-up time and study results.

\section{Bias risk assessment}

The Cochrane Collaboration's tool for assessing the risk of bias was used. The items assessed were random sequence generation, allocation concealment, blinding of the participants and personnel, blinding of the outcome assessment, incomplete outcome data, selective reporting and other biases (Additional file 1: Figure S1). In order to quantify the quality of the articles, we performed a subgroup analysis of quality assessment according to the modified Jadad score (Additional file 13: Table S1). In 
addition, we also conducted a subgroup analysis with reference to the quality evaluation method of Watson et al. [13] (Additional file 14: Table S2).

\section{Trial sequential analysis}

To prevent the constantly updated meta-analysis from increasing the risk of type I errors, we conducted a TSA that could also estimate the amount of information required for such research, thereby stopping similar research in time and preventing the waste of medical resources. We performed a one-sided TSA to summarise and analyse the data of the included studies for the functional outcome with $5 \%$ risk of type I error and $80 \%$ power.

\section{Statistical analysis}

All statistical aspects of the meta-analysis were performed using Review Manager 5.3 software. All our outcomes comprised dichotomous data, and the pooled risk ratios and 95\% confidence intervals of these data were calculated. In terms of statistical heterogeneity, a quantitative analysis was performed using the Mantel-Haenszel $(\mathrm{MH})$ chi-square test and the $I$-square test; when $p$ was $<0.05$ for the $\mathrm{MH}$ chi-square test or $I^{2}$ was $>50 \%$ for the $I$-square test, there was obvious heterogeneity. To evaluate the publication bias, we created funnel plot charts. In addition, we conducted a sensitivity analysis using STATA version 15.1 to determine whether any single study incurred undue weight in the analysis.

\section{Results}

\section{Study selection}

We present the entire search process and the reasons for excluding the ineligible studies in a flowchart in Additional file 3: Figure S3 (Additional file 2: Figure S2). Our search strategy identified 2523 studies: 555 studies were excluded due to duplicate data, 1872 studies were excluded after a review of the abstracts and titles and 88 studies were excluded after a full-text screening. The remaining 23 studies with a total of 2796 patients were included in our final analysis.

\section{Characteristics of the trials}

We included 23 studies that compared patients with TBI in a TH group and a control group. Table 1 shows all the characteristics of the included studies. All the studies were published between 1993 and 2018, with samples ranging from 16 to 495 patients. Of these 23 trials, 22 $[2,6,8,15-33]$ compared the effect of hypothermia treatment with regular treatment or fever control (the target temperature of the $\mathrm{TH}$ group ranged from 32 to $35^{\circ} \mathrm{C}$ ). One trial [34] divided the patients into three groups: deep cooling $\left(20\right.$ to $29^{\circ} \mathrm{C}$ ), mild cooling (30 to $36^{\circ} \mathrm{C}$ ) and a control group. We only included the data for the mild cooling group, which was comparable to the groups in our other included studies. The induction time ranged from "immediately" to 10 days, the hypothermia duration ranged from 1 to 14 days and the follow-up time ranged from 3 to 24 months. Twenty-two $[2,6,8,15-33]$ of these studies included mortality data, and 21 studies [2, 6, 8, 15-23, 25-29, 31-34] reported data on functional outcome (dichotomized GOS or GOSE).

\section{Mortality}

Mortality was reported in 22 studies, which included a total of 2774 patients. Overall, there was no significant difference between the hypothermia group and the normothermia group (RR $0.91,95 \%$ CI $0.80-1.03, p=0.13$ ) (Additional file 3: Figure S3). The funnel plot chart that we created showed no significant difference in publication bias between the two groups (Additional file 4: Figure S4). When we conducted a subgroup analysis according to different populations, we find that $\mathrm{TH}$ is more beneficial for patients in Eastern countries (RR 0.70, 95\% CI 0.58-0.84, $p=0.0002$ ) (Additional file 5: Figure S5).

According to bias score, three studies with a low risk of bias showed a higher mortality in the TH group (RR $1.31,95 \%$ CI 1.05-1.63, $p=0.02$ ), whereas the 19 studies with high risk of bias showed a higher mortality in the control group (RR, 0.75; 95\% CI, 0.65-0.87; $\mathrm{p}=0.0002$ ). There was possible high heterogeneity between the two subgroups $\left(I^{2}=94 \%\right)$ (Fig. 1). According to the modified Jadad quality score, seven studies with high quality showed a higher mortality in the TH group (RR 1.26, 95\% CI 1.04-1.53, $p=0.02$ ), whereas the 15 studies with low quality showed a higher mortality in the control group (RR 0.71, 95\% CI 0.60-0.83, $p<0.0001$ ). There was possible high heterogeneity between the two subgroups $\left(I^{2}=94.9 \%\right)$ (Fig. 2).

Subgroup analyses of early $\mathrm{TH}(<24 \mathrm{~h})$ versus late $\mathrm{TH}(>24 \mathrm{~h})$ When mortality was analysed in terms of the induction time of $\mathrm{TH}$ after TBI, there were significant differences between the subgroups. For the participants with early hypothermia $(<24 h)$, there was significantly greater mortality in the control group than in the TH group (RR $0.83,95 \%$ CI 0.71 to $0.96, p=0.01$ ), with possible low heterogeneity $\left(I^{2}=25 \%\right)$. However, among those participants with $\mathrm{TH}$ induced $\geq 24 \mathrm{~h}$ after TBI, there was no significant difference in mortality between the $\mathrm{TH}$ and control groups (RR 1.12, 95\% CI 0.90 to $1.40, p=0.30$ ) with possible substantial heterogeneity $\left(I^{2}=76 \%\right)$. There was also a possibility of substantial heterogeneity $\left(I^{2}=\right.$ 79.9\%) between the two subgroups (Fig. 3).

Subgroup analyses of $\mathrm{TH}$ for prevention versus treatment When mortality was analysed in terms of hypothermia for prevention or treatment, among those who received 
Table 1 Characteristics of included studies

\begin{tabular}{|c|c|c|c|c|c|c|c|c|c|c|}
\hline \multirow[t]{2}{*}{ Study } & \multicolumn{2}{|c|}{ Population } & \multicolumn{2}{|l|}{ Age } & \multirow[t]{2}{*}{ GCS } & \multirow[t]{2}{*}{ Induction time } & \multirow{2}{*}{$\begin{array}{l}\text { Target } \\
\text { temperature }\end{array}$} & \multirow{2}{*}{$\begin{array}{l}\text { Hypothermia } \\
\text { duration }\end{array}$} & \multirow{2}{*}{$\begin{array}{l}\text { Rewarming } \\
\text { rate }\end{array}$} & \multirow{2}{*}{$\begin{array}{l}\text { Follow-up } \\
\text { time }\end{array}$} \\
\hline & $\mathrm{HT}$ & $\mathrm{CON}$ & $\mathrm{HT}$ & $\mathrm{CON}$ & & & & & & \\
\hline Aibiki et al. [19] & 15 & 11 & $34 \pm 6$ & $38 \pm 8$ & $\leq 8$ & $3-4 h$ & $32-33^{\circ} \mathrm{C}$ & $3-4$ days & $1^{\circ} \mathrm{C} /$ day & 6 months \\
\hline Andrews et al. [2] & 195 & 192 & $37.4 \pm 15.4$ & $36.7 \pm 14.9$ & $\begin{array}{l}3- \\
15\end{array}$ & $3-10$ days & $32-35^{\circ} \mathrm{C}$ & $48 \mathrm{~h}$ & $0.25^{\circ} \mathrm{C} / \mathrm{h}$ & 6 months \\
\hline Clifton et al. [15] & 24 & 22 & NM & NM & $4-7$ & $6 \mathrm{~h}$ & $32-33^{\circ} \mathrm{C}$ & $48 \mathrm{~h}$ & $1{ }^{\circ} \mathrm{C} / 4 \mathrm{~h}$ & NM \\
\hline Clifton et al. [21] & 190 & 178 & $31 \pm 12$ & $32 \pm 13$ & $3-8$ & $6 \mathrm{~h}$ & $32.5-34.0^{\circ} \mathrm{C}$ & $48 \mathrm{~h}$ & $0.5^{\circ} \mathrm{C} / 2 \mathrm{~h}$ & 6 months \\
\hline Clifton et al. [31] & 52 & 45 & $26 \pm 9$ & $31 \pm 11$ & $3-8$ & $2.5 \mathrm{~h}$ & $33^{\circ} \mathrm{C}$ & $48 \mathrm{~h}$ & $0.5^{\circ} \mathrm{C} / 2 \mathrm{~h}$ & 6 months \\
\hline Cooper et al. [8] & 256 & 239 & $35 \pm 13.5$ & $34.1 \pm 13.4$ & $<9$ & Rapidly & $33 \pm 0.5^{\circ} \mathrm{C}$ & $72 \mathrm{~h}$ & $0.25^{\circ} \mathrm{C} / \mathrm{h}$ & 6 months \\
\hline Harris et al. [30] & 12 & 13 & $38.1 \pm 15$ & $33.2 \pm 20$ & $\leq 8$ & $24 \mathrm{~h}$ & $33^{\circ} \mathrm{C}$ & $24 \mathrm{~h}$ & $0.5^{\circ} \mathrm{C} / 3 \mathrm{~h}$ & NM \\
\hline $\begin{array}{l}\text { Hashiguchi et al. } \\
\text { [23] }\end{array}$ & 9 & 8 & $29.0 \pm 14.9$ & $39.1 \pm 13.2$ & $<8$ & $\begin{array}{l}\text { As soon as } \\
\text { possible }\end{array}$ & $33.5-34.5^{\circ} \mathrm{C}$ & $48 \mathrm{~h}$ & $1^{\circ} \mathrm{C} /$ day & 6 months \\
\hline Idris et al. [34] & 9 & 13 & $17.3-40.5$ & $35.0-56.1$ & $6-7$ & NM & $\begin{array}{l}20-29^{\circ} \mathrm{C}, 30- \\
36^{\circ} \mathrm{C}\end{array}$ & $24-48 h$ & NM & 6 months \\
\hline Jiang et al. [20] & 43 & 44 & Mean 42.2 & Mean 40.6 & $\leq 8$ & $15 \mathrm{~h}$ & $33-35^{\circ} \mathrm{C}$ & 3-14 days & $\leq 1^{\circ} \mathrm{C} / \mathrm{h}$ & 12 months \\
\hline Liu et al. [28] & 43 & 23 & NM & NM & $\leq 8$ & $2 \mathrm{~h}$ & $33-35^{\circ} \mathrm{C}$ & 3 days & Passive & 24 months \\
\hline $\begin{array}{l}\text { Maekawa et al. } \\
\text { [32] }\end{array}$ & 94 & 45 & $39 \pm 19$ & $39 \pm 18$ & $4-8$ & $92 \mathrm{~h}$ & $32-34^{\circ} \mathrm{C}$ & $\geq 72 \mathrm{~h}$ & $<1^{\circ} \mathrm{C} /$ day & 6 months \\
\hline Marion et al. [17] & 40 & 42 & $31 \pm 12$ & $35 \pm 15$ & $3-7$ & $10 \mathrm{~h}$ & $32-33^{\circ} \mathrm{C}$ & $24 \mathrm{~h}$ & Passive & 12 months \\
\hline $\begin{array}{l}\text { Meissner et al. } \\
\text { [24] }\end{array}$ & 11 & 13 & Median 30 & Median 48 & $\leq 9$ & $8 \mathrm{~h}$ & $32-33^{\circ} \mathrm{C}$ & $24-48 \mathrm{~h}$ & NM & NM \\
\hline Qiu et al. [26] & 43 & 43 & Mean 40.0 & Mean 42.3 & $<8$ & 4.3 days & $33-35^{\circ} \mathrm{C}$ & $3-5$ days & Passive & 24 months \\
\hline Qiu et al. [29] & 40 & 40 & Mean 41.3 & Mean 40.2 & $\leq 8$ & Immediately & $33-35^{\circ} \mathrm{C}$ & 4 days & Passive & 12 months \\
\hline Shiozaki et al. [16] & 16 & 17 & $35.3 \pm 15.3$ & $35.4 \pm 12.6$ & $\leq 8$ & $24 \mathrm{~h}$ & $33.5-34.5^{\circ} \mathrm{C}$ & 2 days & Passive & 6 months \\
\hline Shiozaki et al. [18] & 8 & 8 & $31.4 \pm 12.7$ & $40.3 \pm 23.1$ & $\leq 8$ & $2 \mathrm{~h}$ & $33.5-34.5^{\circ} \mathrm{C}$ & $48 \mathrm{~h}$ & $1^{\circ} \mathrm{C} /$ day & 6 months \\
\hline Shiozaki et al. [22] & 45 & 46 & $35 \pm 20$ & $42 \pm 17$ & $\leq 8$ & $\begin{array}{l}\text { As quickly as } \\
\text { possible }\end{array}$ & $33.5-34.5^{\circ} \mathrm{C}$ & $48 \mathrm{~h}$ & $1^{\circ} \mathrm{C} /$ day & 3 months \\
\hline Smrcka et al. [27] & 35 & 37 & NM & NM & $<8$ & $15 \mathrm{~h}$ & $34^{\circ} \mathrm{C}$ & $72 \mathrm{~h}$ & Passive & 6 months \\
\hline Tang et al. [33] & 30 & 30 & $\begin{array}{l}42.47 \pm \\
13.93\end{array}$ & $\begin{array}{l}39.67 \pm \\
15.26\end{array}$ & $3-8$ & Within $24 \mathrm{~h}$ & $32-35^{\circ} \mathrm{C}$ & $48 \mathrm{~h}$ & $0.25^{\circ} \mathrm{C} / \mathrm{h}$ & $\begin{array}{l}6-48 \\
\text { months }\end{array}$ \\
\hline Zhao et al. [6] & 40 & 41 & $36.9 \pm 14.8$ & $37.5 \pm 15.2$ & $3-8$ & $3-5 h$ & $32.5-33^{\circ} \mathrm{C}$ & $72 \mathrm{~h}$ & Passive & 3 months \\
\hline Zhi et al. [25] & 198 & 198 & $43 \pm 17$ & $42 \pm 19$ & $\leq 8$ & Within $24 \mathrm{~h}$ & $32-35^{\circ} \mathrm{C}$ & $1-7$ days & $1^{\circ} \mathrm{C} / 4 \mathrm{~h}$ & 6 months \\
\hline
\end{tabular}

HT therapeutic hypothermia, CON control, GCS Glasgow Coma Score, NM not mentioned

$\mathrm{TH}$ for treatment there was significantly greater mortality in the control group than in the TH group (RR 0.66, $95 \%$ CI 0.49 to $0.88, p=0.006$ ), with possible moderate heterogeneity $\left(I^{2}=59 \%\right)$. However, among those who received $\mathrm{TH}$ for prevention, there was no significant difference in mortality between the $\mathrm{TH}$ and control groups (RR $1.12,95 \%$ CI 0.93 to $1.36, p=0.23$ ) with possible low heterogeneity $\left(I^{2}=0 \%\right)$. There was also a possibility substantial heterogeneity $\left(I^{2}=88.7 \%\right)$ between the subgroups (Fig. 4).

\section{Subgroup analyses using $\mathrm{TH}$ in post-craniectomy versus non-craniectomy}

When mortality was analysed in terms of using $\mathrm{TH}$ in post-craniectomy or non-craniectomy patients, among those participants who received $\mathrm{TH}$ in post-craniectomy, there was lower mortality in the $\mathrm{TH}$ group than in the control group (RR 0.69, 95\% CI 0.48 to $1.00, p=0.05$ ), with possible low heterogeneity $\left(I^{2}=23 \%\right)$. However, among those participants who received $\mathrm{TH}$ without a craniectomy for TBI, there was no significant difference in mortality between the $\mathrm{TH}$ and control groups (RR $1.03,95 \%$ CI 0.87 to $1.21, p=0.75$ ) with possible low heterogeneity $\left(I^{2}=0 \%\right)$. There was also a possibility of substantial heterogeneity $\left(I^{2}=73.4 \%\right)$ between the two subgroups (Fig. 5).

\section{Unfavourable functional outcome}

The impact of $\mathrm{TH}$ on functional outcome was evaluated in 21 trials that included a total of 2721 patients. A total of 1409 patients were assigned to the TH group, 698 of whom had an unfavourable functional outcome. A total of 1312 patients were assigned to the control group; 763 of these patients had an unfavourable functional 


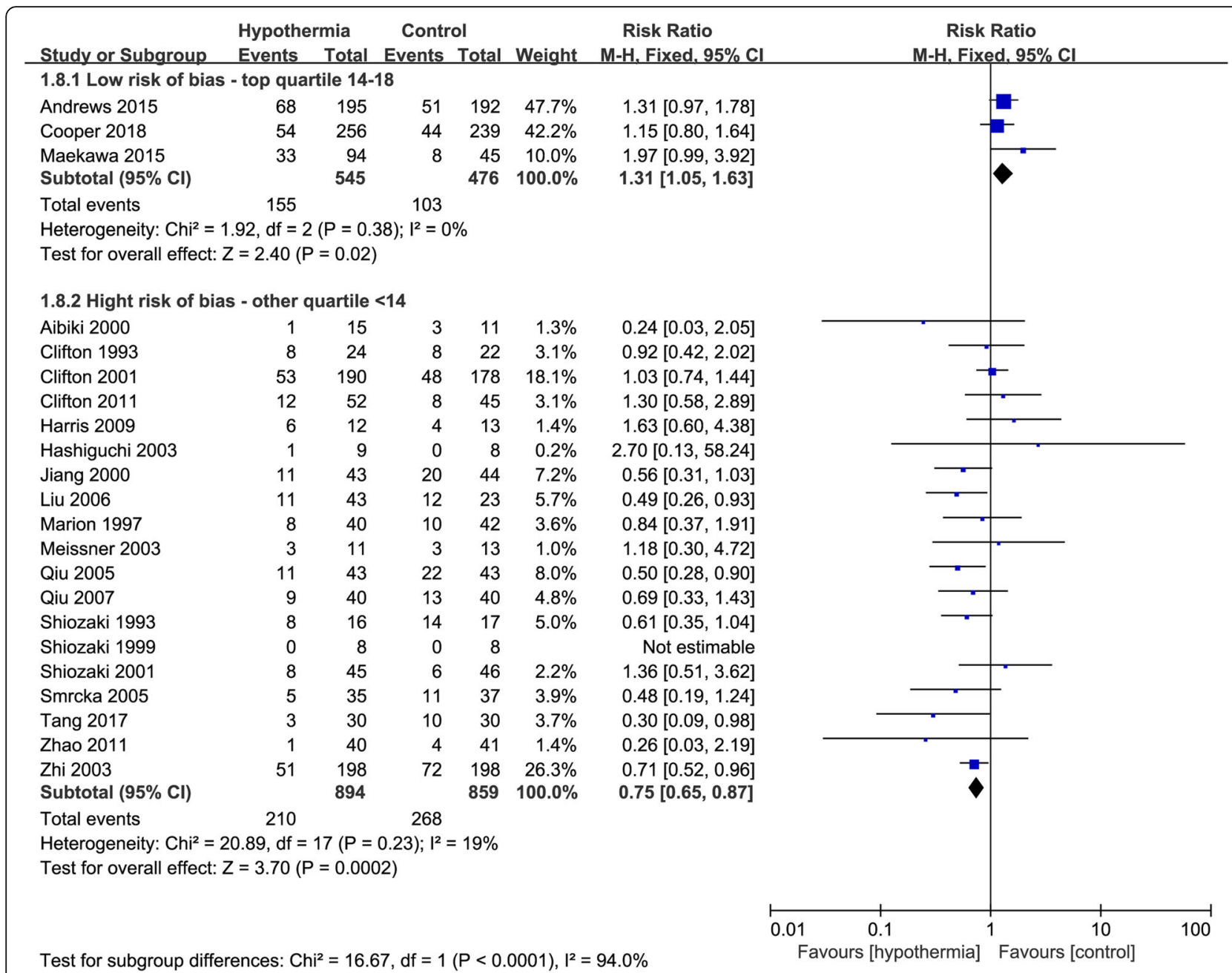

Fig. 1 Forest plot of mortality in the low risk group or high risk group. $\mathrm{M}-\mathrm{H}$, Mantel-Haenszel method; $\mathrm{Cl}$, confidence interval

outcome. The funnel plot chart that we created showed no significant difference in publication bias between the two groups (Additional file 6: Figure S6). The results showed that the risk of an unfavourable functional outcome was significantly reduced in the $\mathrm{TH}$ group versus the control group (RR 0.78, 95\% CI 0.67 to $0.91, p=$ 0.001) (Fig. 6). The TSA showed that the required information size (RIS) for such studies was 3864 patients. Furthermore, the $Z$-curve crossed both the traditional boundary and the TSA line but did not reach the RIS line, which shows that the current number of trials may have reached a positive conclusion regarding the neurological prognosis (Additional file 7: Figure S7).

\section{Secondary outcomes}

Thirteen studies $[2,8,15,16,18,20,23,26,28,29,31-33]$ reported pneumonia as an outcome. Overall, there was a significant increase in the risk of pneumonia with $\mathrm{TH}$ management (RR 1.48, 95\% CI 1.11 to $1.97, p=0.007$ ).
There was possible substantial heterogeneity $\left(I^{2}=74 \%\right)$ between the TH group and the control group (Fig. 7).

\section{Sensitivity analysis}

We systematically and qualitatively analysed the sensitivity across the included studies to determine the influence of individual trials on the results. We did not detect a significant impact from any single study and confirmed the direction of the results (Additional file 8: Figure S8, Additional file 9: Figure S9 and Additional file 10: Figure S10).

\section{Discussion}

TH management remains controversial for patients with TBI [11, 35]. Despite extensive research, there is no high-quality evidence that hypothermia is beneficial to TBI patients, as is to cardiac arrest [36]. Similar to a recent meta-analysis, our meta-analysis demonstrated that TH could cause more mortality in the subgroup of highquality studies. And TH initiated within $24 \mathrm{~h}$ could reduce mortality in patients with TBI [13]. Furthermore, 


\begin{tabular}{|c|c|c|c|c|c|c|c|c|c|}
\hline \multirow{2}{*}{$\begin{array}{l}\text { Study or Subgroup } \\
\text { 1.9.1 high-quality }\end{array}$} & \multicolumn{2}{|c|}{ Hypothermia } & \multicolumn{2}{|c|}{ Control } & Weight & $\begin{array}{l}\text { Risk Ratio } \\
\text { M-H, Fixed, } 95 \% \mathrm{Cl}\end{array}$ & \multicolumn{3}{|c|}{$\begin{array}{l}\text { Risk Ratio } \\
\text { M-H, Fixed, 95\% Cl }\end{array}$} \\
\hline & & & & & & & & & \\
\hline Andrews 2015 & 68 & 195 & 51 & 192 & $37.2 \%$ & $1.31[0.97,1.78]$ & & - & \\
\hline Clifton 1993 & 8 & 24 & 8 & 22 & $6.0 \%$ & $0.92[0.42,2.02]$ & & & \\
\hline Clifton 2011 & 12 & 52 & 8 & 45 & $6.2 \%$ & $1.30[0.58,2.89]$ & & - & \\
\hline Cooper 2018 & 54 & 256 & 44 & 239 & $32.9 \%$ & $1.15[0.80,1.64]$ & & - & \\
\hline Harris 2009 & 6 & 12 & 4 & 13 & $2.8 \%$ & $1.63[0.60,4.38]$ & & & \\
\hline Maekawa 2015 & 33 & 94 & 8 & 45 & $7.8 \%$ & $1.97[0.99,3.92]$ & & & \\
\hline Marion 1997 & 8 & 40 & 10 & 42 & $7.1 \%$ & $0.84[0.37,1.91]$ & & 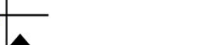 & \\
\hline Subtotal $(95 \% \mathrm{Cl})$ & & 673 & & 598 & $100.0 \%$ & $1.26[1.04,1.53]$ & & $\checkmark$ & \\
\hline Total events & 189 & & 133 & & & & & & \\
\hline \multicolumn{10}{|c|}{ Heterogeneity: $\mathrm{Chi}^{2}=3.80, \mathrm{df}=6(P=0.70) ; 1^{2}=0 \%$} \\
\hline \multicolumn{10}{|c|}{ Test for overall effect: $Z=2.33(P=0.02)$} \\
\hline \multicolumn{10}{|l|}{ 1.9.2 low-quality } \\
\hline Aibiki 2000 & 1 & 15 & 3 & 11 & $1.4 \%$ & $0.24[0.03,2.05]$ & & & \\
\hline Clifton 2001 & 53 & 190 & 48 & 178 & $20.4 \%$ & $1.03[0.74,1.44]$ & & - & \\
\hline Hashiguchi 2003 & 1 & 9 & 0 & 8 & $0.2 \%$ & $2.70[0.13,58.24]$ & & & \\
\hline Jiang 2000 & 11 & 43 & 20 & 44 & $8.1 \%$ & $0.56[0.31,1.03]$ & & & \\
\hline Liu 2006 & 11 & 43 & 12 & 23 & $6.4 \%$ & $0.49[0.26,0.93]$ & & & \\
\hline Meissner 2003 & 3 & 11 & 3 & 13 & $1.1 \%$ & $1.18[0.30,4.72]$ & & & \\
\hline Qiu 2005 & 11 & 43 & 22 & 43 & $9.1 \%$ & $0.50[0.28,0.90]$ & 7 & & \\
\hline Qiu 2007 & 9 & 40 & 13 & 40 & $5.4 \%$ & $0.69[0.33,1.43]$ & & - & \\
\hline Shiozaki 1993 & 8 & 16 & 14 & 17 & $5.6 \%$ & $0.61[0.35,1.04]$ & & & \\
\hline Shiozaki 1999 & 0 & 8 & 0 & 8 & & Not estimable & & & \\
\hline Shiozaki 2001 & 8 & 45 & 6 & 46 & $2.4 \%$ & $1.36[0.51,3.62]$ & & & \\
\hline Smrcka 2005 & 5 & 35 & 11 & 37 & $4.4 \%$ & $0.48[0.19,1.24]$ & & & \\
\hline Tang 2017 & 3 & 30 & 10 & 30 & $4.1 \%$ & $0.30[0.09,0.98]$ & & & \\
\hline Zhao 2011 & 1 & 40 & 4 & 41 & $1.6 \%$ & $0.26[0.03,2.19]$ & & & \\
\hline Zhi 2003 & 51 & 198 & 72 & 198 & $29.6 \%$ & $0.71[0.52,0.96]$ & -- & & \\
\hline Subtotal $(95 \% \mathrm{Cl})$ & & 766 & & 737 & $100.0 \%$ & $0.71[0.60,0.83]$ & $\bullet$ & & \\
\hline Total events & 176 & & 238 & & & & & & \\
\hline \multirow{2}{*}{\multicolumn{10}{|c|}{$\begin{array}{l}\text { Heterogeneity: } \mathrm{Chi}^{2}=15.92, \mathrm{df}=13(P=0.25) ; \mathrm{I}^{2}=18 \% \\
\text { Test for overall effect: } Z=4.14(P<0.0001)\end{array}$}} \\
\hline & & & & & & & & & \\
\hline & & & & & & & 0.01 & 10 & 100 \\
\hline Test for subgroup diffe & rences: $\mathrm{Ch}$ & $i^{2}=19.7$ & $79, d f=1$ & $(P<0$. & $.00001),\left.\right|^{2}=$ & $=94.9 \%$ & Favours [hypothermia] & Favours [control] & \\
\hline
\end{tabular}

we also find TBI patients benefit from $\mathrm{TH}$ when hypothermia is used for therapy instead of prophylaxis. Additionally, post-craniectomy TBI patients may benefit more from $\mathrm{TH}$ than patients who have not received a craniectomy. In terms of functional outcome, our metaanalysis is consistent with previous meta-results $[2,12]$. Patients with TBI can show improved neurological outcomes with $\mathrm{TH}$ within $72 \mathrm{~h}$ of injury [8].

Some RCTs suggest that elevated ICP is associated with worsening outcomes in patients with TBI [37, 38]. Elevated ICP may result in decreased cerebral perfusion pressure and cerebral blood flow, which may further lead to hypoxic-ischaemic brain damage [39]. Many studies have shown that $\mathrm{TH}$ can play a role in neuroprotection in many ways, mainly because hypothermia can reduce ICP, reduce the brain metabolic rate, reduce the blood flow in the brain, change the release of neurotransmitters and maintain the function of the blood-brain barrier $[40,41]$. Moreover, TH can reduce the inflammatory response and biochemical cascade that is activated early after TBI [42], thereby limiting secondary brain injury $[43,44]$. A study by Roman et al. showed that $\mathrm{TH}$ can improve the functional prognosis of GOS (4-5) by reducing ICP [7]. Our study also found that hypothermia can improve the patient's functional outcomes.

However, some studies have shown that hypothermia sometimes plays an adverse role. Several recent multicentre large RCT studies have shown that TH not only failed to reduce patient 6 -month mortality but may also be harmful to patients with lesser damage [2, 8, 9, 32]. Longterm hypothermia is considered a form of immunosuppression that increases the infection rate of pneumonia and sepsis [45]. In addition, it has been reported in the literature that hypothermia can cause propofol infusion syndrome because propofol can reduce liver metabolism; this may be an important cause of fatal symptoms at low temperatures [46]. It has also been reported that low temperatures can affect the metabolism of certain drugs, including muscle relaxants such as atracurium, which may further affect 6-month mortality [47]. The CRASH study, 


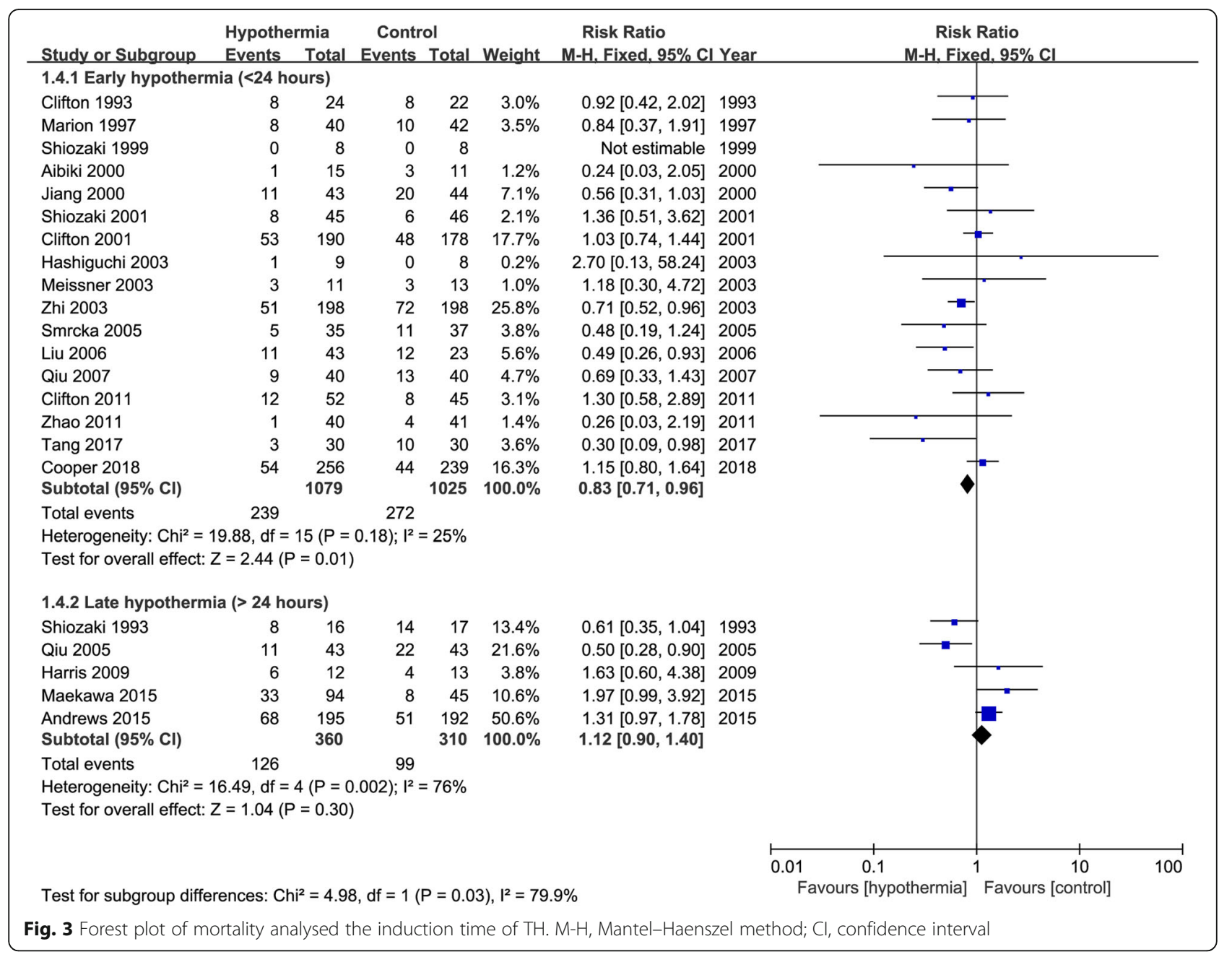

a large multicentre trial, also found a lower 6-month survival rate in the hypothermia group and a higher 2-week mortality rate in patients treated with methylprednisolone [48]. It has been shown that the use of steroidal antipyretics may also be one of the important factors that influence mortality. The results of our subgroup analysis also showed that high-quality studies suggested that $\mathrm{TH}$ can cause an increase in mortality.

We observed smaller studies may note some "benefits" from hypothermia while the more structured large RCTs have failed; we believe it may be because the smaller studies are mostly with small sample size and singlecentre. Through the sample size-bias curve, we found that the sample size and the bias score showed a significant positive correlation after the abnormal point was removed (Additional file 11: Figure S11), that is, as the sample size increased, the bias gradually decreased. However, the study of Zhi et al. has a large sample size but a low bias score, and different to the results of other studies with large sample size, we suspect that it may invite bias into the results. The column chart about research centres and bias also support our conjecture (Additional file 12: Figure S12). But since all the included studies meet the inclusion criteria for our metaanalysis, there is no reason to remove any RCT study, which is a limitation of our research. So we recommend more large multicentre RCTs to continue this research.

Why is there controversy regarding $\mathrm{TH}$ management for patients with TBI? First, it seems that the induction time of $\mathrm{TH}$ is the key point. Our meta-analysis found that both survival rates and functional outcomes will benefit if $\mathrm{TH}$ is administered within $24 \mathrm{~h}$ after TBI. In animal experiments, the most obvious link between intracranial temperature changes and nerve injury occurred within the first $24 \mathrm{~h}[49,50]$. When TH is applied within $24 \mathrm{~h}$ after TBI, it may be possible to control the increase of ICP earlier, thereby reducing intracranial nerve injury and improving the functional prognosis of patients. There are data indicating that hypothermia may regulate both the JNK signalling cascade via XIAP and the preconditioning pathways that activate caspases. Thus, hypothermia mediates TNFR1 responses via early 


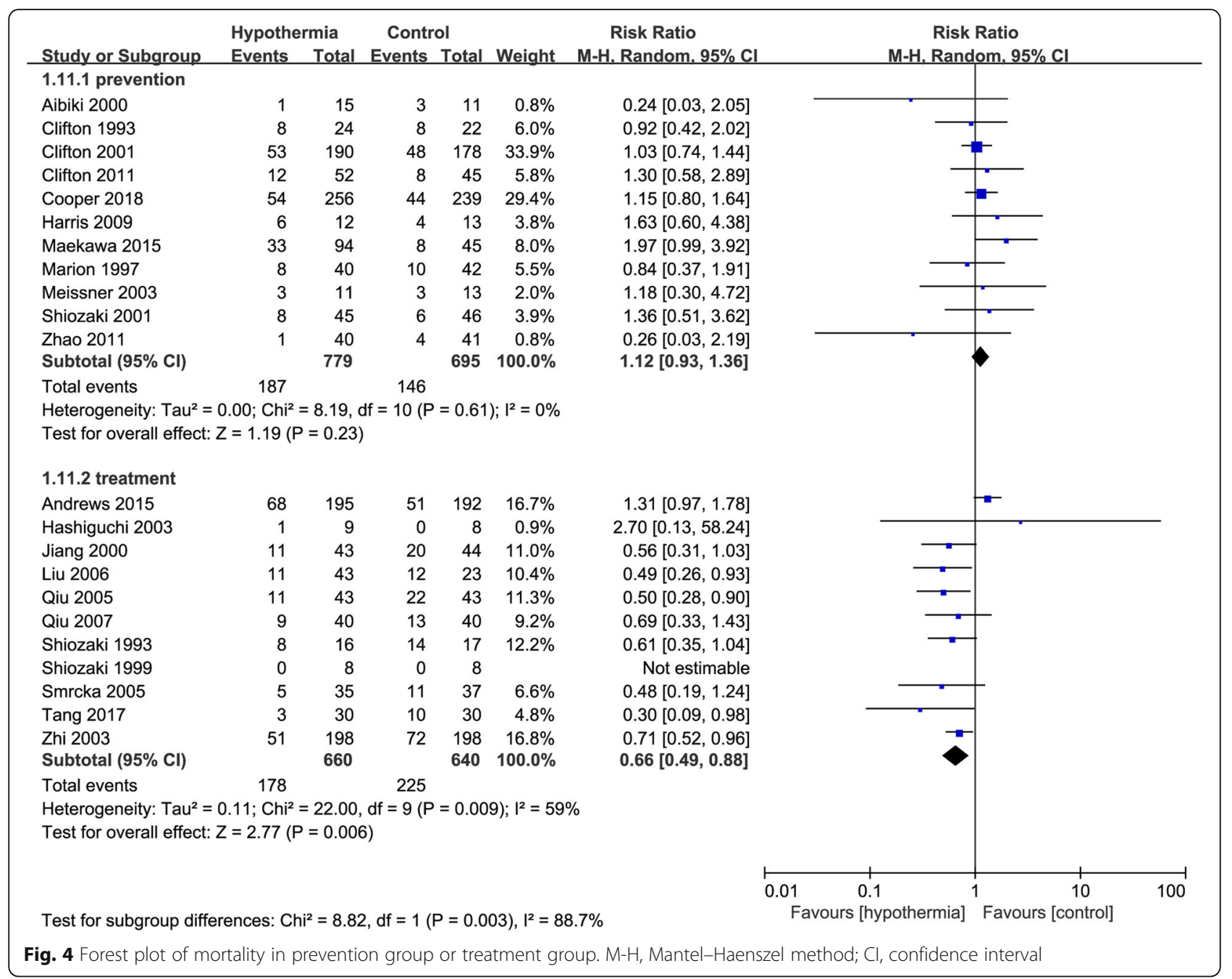

activation of the JNK signalling pathway and caspase-3, leading to endogenous neuroprotective events [51]. Recent studies by Watson et al. also supported early hypothermia in patients with TBI [13]. At present, there is no consensus regarding when $\mathrm{TH}$ management should be used after TBI. After the occurrence of TBI, the severity of numerous destructive biochemical cascades plays a decisive role in the survival of nerve cells [43]. $\mathrm{TH}$ is an effective protective mechanism to inhibit these reactions. We believe that $\mathrm{TH}$ management within $24 \mathrm{~h}$ is conducive to maximally limiting the infinite expansion of these cascades in a short period of time, thereby avoiding risks, and when the TH time is later (more than $24 \mathrm{~h}$ ), patients may have more serious damage, and ICP may be more difficult to control; such destructive reactions have been irreversible.

A subgroup analysis of $\mathrm{TH}$ for prevention or treatment suggests that $\mathrm{TH}$ may be more effective in reducing mortality when used for therapeutic purposes. We believe that the hypothermia applied in patients with TBI after cerebral oedema, increased intracranial pressure or craniotomy is defined as a therapeutic effect, and the application of hypothermia as soon as possible without relevant complications is a preventive effect. These two concepts have not been clearly defined internationally, and we need to recognise the subjectivity of this subgroup analysis. Moreover, the subgroup analysis of post-craniotomy showed that $\mathrm{TH}$ after surgery had a tendency to reduce mortality. Previous studies have reported that the use of mild hypothermia as a preventive application of neuroprotective agents has also failed; prophylactic hypothermia is not recommended to improve final outcomes [52]. Clifton et al. also found that, compared with diffuse brain injury, TH may play a better effect in those with surgically evacuated haematomas [31]. It has also been confirmed at the experimental level that intra-ischaemic hypothermia after haematoma removal is associated with improved outcomes [53]. 


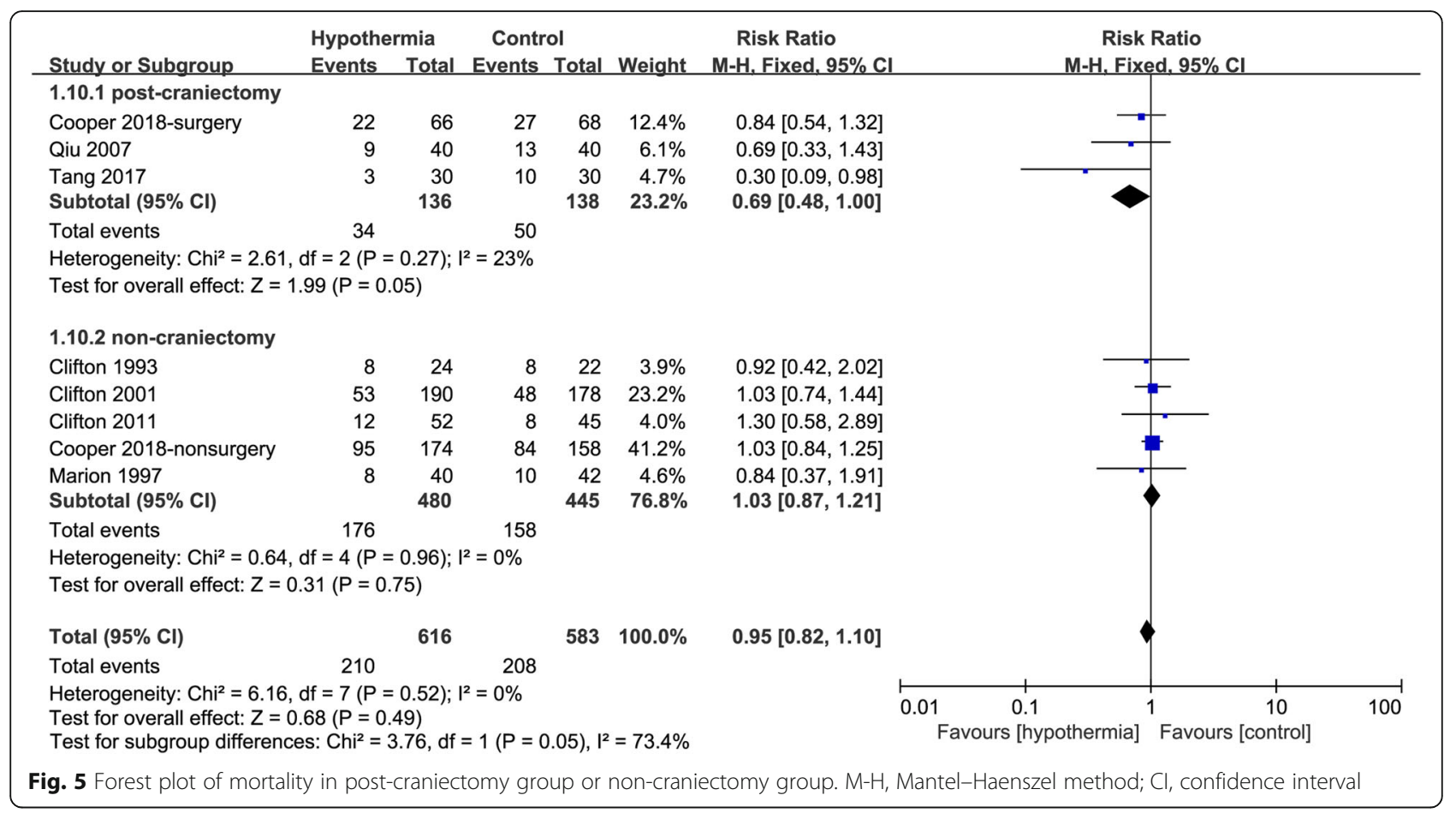

\begin{tabular}{|c|c|c|c|c|c|c|c|c|c|c|}
\hline \multirow{2}{*}{ Study or Subgroup } & \multicolumn{2}{|c|}{ Hypothermia } & \multicolumn{2}{|c|}{ Control } & \multicolumn{3}{|c|}{ Risk Ratio } & \multirow{2}{*}{\multicolumn{3}{|c|}{$\begin{array}{c}\text { Risk Ratio } \\
\mathrm{M}-\mathrm{H} . \text { Random. } 95 \% \mathrm{Cl}\end{array}$}} \\
\hline & Events & Iotal & & & & M-H, Random. $95 \% \mathrm{Cl}$ & IYear & & & \\
\hline Shiozaki 1993 & 10 & 16 & 16 & 17 & $5.3 \%$ & $0.66[0.45,0.99]$ & 1993 & 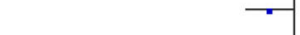 & & \\
\hline Clifton 1993 & 11 & 24 & 14 & 22 & $4.1 \%$ & $0.72[0.42,1.23]$ & 1993 & $\longrightarrow$ & & \\
\hline Marion 1997 & 18 & 40 & 28 & 42 & $5.3 \%$ & $0.68[0.45,1.01]$ & 1997 & $\rightarrow$ & & \\
\hline Shiozaki 1999 & 2 & 8 & 1 & 8 & $0.4 \%$ & $2.00[0.22,17.89]$ & 1999 & & & \\
\hline Aibiki 2000 & 3 & 15 & 7 & 11 & $1.5 \%$ & $0.31[0.10,0.95]$ & 2000 & & & \\
\hline Jiang 2000 & 23 & 43 & 32 & 44 & $6.0 \%$ & $0.74[0.53,1.03]$ & 2000 & & & \\
\hline Clifton 2001 & 108 & 190 & 102 & 178 & $7.7 \%$ & $0.99[0.83,1.18]$ & 2001 & & & \\
\hline Shiozaki 2001 & 24 & 45 & 19 & 46 & $4.9 \%$ & $1.29[0.83,2.00]$ & 2001 & & & \\
\hline Hashiguchi 2003 & 3 & 9 & 1 & 8 & $0.5 \%$ & $2.67[0.34,20.78]$ & 2003 & & & \\
\hline Zhi 2003 & 76 & 198 & 123 & 198 & $7.4 \%$ & $0.62[0.50,0.76]$ & 2003 & - & & \\
\hline Qiu 2005 & 15 & 43 & 27 & 43 & $4.6 \%$ & $0.56[0.35,0.89]$ & 2005 & 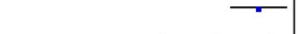 & & \\
\hline Smrcka 2005 & 5 & 35 & 19 & 37 & $2.2 \%$ & $0.28[0.12,0.66]$ & 2005 & - & & \\
\hline Liu 2006 & 15 & 43 & 15 & 23 & $4.3 \%$ & $0.53[0.32,0.89]$ & 2006 & $\longrightarrow$ & & \\
\hline Qiu 2007 & 12 & 40 & 21 & 40 & $3.9 \%$ & $0.57[0.33,1.00]$ & 2007 & & & \\
\hline Zhao 2011 & 10 & 40 & 20 & 41 & $3.4 \%$ & $0.51[0.28,0.95]$ & 2011 & " & & \\
\hline Clifton 2011 & 19 & 52 & 25 & 45 & $4.9 \%$ & $0.66[0.42,1.02]$ & 2011 & - & & \\
\hline Idris 2014 & 7 & 9 & 11 & 13 & $5.1 \%$ & $0.92[0.60,1.40]$ & 2014 & & & \\
\hline Andrews 2015 & 142 & 195 & 120 & 192 & $8.1 \%$ & $1.17[1.01,1.34]$ & 2015 & & - & \\
\hline Maekawa 2015 & 50 & 94 & 23 & 48 & $5.8 \%$ & $1.11[0.78,1.58]$ & 2015 & & & \\
\hline Tang 2017 & 22 & 30 & 24 & 30 & $6.6 \%$ & $0.92[0.69,1.21]$ & 2017 & & & \\
\hline Cooper 2018 & 123 & 240 & 115 & 226 & $7.7 \%$ & $1.01[0.84,1.20]$ & 2018 & & & \\
\hline Total $(95 \% \mathrm{Cl})$ & & 1409 & & 1312 & $100.0 \%$ & $0.78[0.67,0.91]$ & & $\bullet$ & & \\
\hline Total events & 698 & & 763 & & & & & & & \\
\hline $\begin{array}{l}\text { Heterogeneity: } \operatorname{Tau}^{2}= \\
\text { Test for overall effect: }\end{array}$ & $\begin{array}{l}0.07 ; \mathrm{Chi}^{2} \\
\mathrm{Z}=3.26(\mathrm{~F}\end{array}$ & $\begin{array}{l}=68.01, \\
=0.001\end{array}$ & $d f=20($ & $P<0.00$ & 0001); $1^{2}=$ & $71 \%$ & & $\begin{array}{lll}0.01 & 0.1 \\
& \text { Favours [hypothermia] }\end{array}$ & $\begin{array}{c}10 \\
\text { Favours [control] }\end{array}$ & 100 \\
\hline
\end{tabular}




\begin{tabular}{|c|c|c|c|c|c|c|c|c|c|c|}
\hline \multirow[b]{2}{*}{ Study or Subgroup } & \multicolumn{2}{|c|}{ Hypothermia } & \multicolumn{2}{|c|}{ Control } & \multicolumn{2}{|c|}{ Risk Ratio } & \multirow{2}{*}{\multicolumn{4}{|c|}{$\begin{array}{c}\text { Risk Ratio } \\
\text { M-H. Random, } 95 \% \mathrm{Cl}\end{array}$}} \\
\hline & Events & Total & Events & Total & Weight & M-H, Random, $95 \% \mathrm{Cl}$ & 1 Year & & & \\
\hline Clifton 1993 & 11 & 24 & 9 & 22 & $7.7 \%$ & $1.12[0.58,2.18]$ & 1993 & - & & \\
\hline Shiozaki 1993 & 9 & 16 & 6 & 17 & $6.7 \%$ & $1.59[0.73,3.46]$ & 1993 & & & \\
\hline Shiozaki 1999 & 5 & 8 & 1 & 8 & $1.9 \%$ & $5.00[0.74,33.78]$ & 1999 & & & \\
\hline Jiang 2000 & 16 & 43 & 14 & 44 & $8.5 \%$ & $1.17[0.65,2.09]$ & 2000 & & & \\
\hline Hashiguchi 2003 & 8 & 9 & 2 & 8 & $3.9 \%$ & $3.56[1.05,12.07]$ & 2003 & & & \\
\hline Qiu 2005 & 26 & 43 & 14 & 43 & $9.5 \%$ & $1.86[1.13,3.04]$ & 2005 & & $\longrightarrow$ & \\
\hline Liu 2006 & 13 & 43 & 8 & 23 & $7.2 \%$ & $0.87[0.42,1.79]$ & 2006 & & & \\
\hline Qiu 2007 & 23 & 40 & 13 & 40 & $9.2 \%$ & $1.77[1.05,2.98]$ & 2007 & & & \\
\hline Clifton 2011 & 29 & 52 & 31 & 45 & $11.4 \%$ & $0.81[0.59,1.11]$ & 2011 & $\rightarrow$ & & \\
\hline Andrews 2015 & 92 & 195 & 32 & 192 & $11.0 \%$ & $2.83[2.00,4.01]$ & 2015 & & $\mp$ & \\
\hline Maekawa 2015 & 3 & 94 & 1 & 48 & $1.5 \%$ & $1.53[0.16,14.34]$ & 2015 & & & \\
\hline Tang 2017 & 20 & 30 & 11 & 30 & $9.0 \%$ & $1.82[1.07,3.10]$ & 2017 & & & \\
\hline Cooper 2018 & 143 & 260 & 123 & 240 & $12.6 \%$ & $1.07[0.91,1.27]$ & 2018 & & 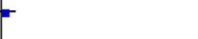 & \\
\hline Total $(95 \% \mathrm{Cl})$ & & 857 & & 760 & $100.0 \%$ & $1.48[1.11,1.97]$ & & & 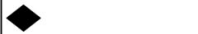 & \\
\hline Total events & 398 & & 265 & & & & & & & \\
\hline $\begin{array}{l}\text { Heterogeneity: } \mathrm{Tau}^{2}= \\
\text { Test for overall effect: }\end{array}$ & $\begin{array}{l}0.16 ; \mathrm{Chi}^{2} \\
\mathrm{z}=2.70(\mathrm{~F}\end{array}$ & $\begin{array}{l}=46.69, \\
=0.007\end{array}$ & $d f=12(P$ & $>0.0$ & 10001); $1^{2}=$ & $74 \%$ & & $\begin{array}{lll}0.01 & 0.1 & 1 \\
& \text { Favours [hypothermia] }\end{array}$ & $\begin{array}{c}10 \\
\text { Favours [control] }\end{array}$ & 100 \\
\hline
\end{tabular}

Through the analysis of the above two subgroups, we hypothesise that we can use hypothermia as a treatment for TBI patients while evacuating the haematoma and after cranietomy, which can effectively reduce the mortality rate.

We need to discuss some of the limitations of our work. First, although we performed a comprehensive database search and a manual search and made a funnel plot, and the funnel plot had symmetry, we did not search the grey literature or contact authors to confirm whether there were any unpublished studies. Therefore, we still cannot rule out the existence of a publication bias. Second, the inclusion criteria for each group of trials included in this study were not completely consistent, which may have led to heterogeneity in the observations. The forest plot shows that the difference in weight is relatively large, which may affect the final result to some extent. Finally, we found substantial heterogeneity in some of the outcomes. We tried to reduce clinical and methodological heterogeneity through different subgroup analyses; however, some analyses did not have an obvious effect, and the heterogeneity was still high. Therefore, we used a random effects model instead of a fixed effects model to address the observed heterogeneity. Despite such differences, our sensitivity analysis identified no outlier studies, hinting that our results were relatively reliable.

\section{Conclusions}

Our meta-analysis demonstrated that $\mathrm{TH}$ did not reduce but might increase the mortality rate of patients with TBI in some high-quality studies. However, TBI patients with elevated ICP could benefit from hypothermia in therapy instead of in prophylaxis when initiated within $24 \mathrm{~h}$, which may require further research to confirm.

\section{Supplementary information}

Supplementary information accompanies this paper at https://doi.org/10. 1186/s13054-019-2667-3.

Additional file 1: Figure S1. Risk of bias summary review authors' judgement about each risk of bias item for each included study. Red, high risk; green, low risk; yellow, unclear

Additional file 2: Figure S2. Study flow diagram detailing the literature search. GOS = Glasgow Outcome Scale

Additional file 3: Figure S3. Risk ratio of mortality in the TH group versus control group. $\mathrm{M}-\mathrm{H}=$ Mantel-Haenszel method, $\mathrm{Cl}=$ confidence interval

Additional file 4: Figure S4. The funnel plot for mortality. SE = standard error, $\mathrm{RR}=$ risk ratio (equivalently, relative risk)

Additional file 5: Figure S5. Forest plot of mortality analyzed different populations. $\mathrm{M}-\mathrm{H}=$ Mantel-Haenszel method, $\mathrm{Cl}=$ confidence interval

Additional file 6: Figure S6. The funnel plot for unfavorable functional outcome. $\mathrm{SE}=$ standard error, $\mathrm{RR}=$ risk ratio (equivalently, relative risk)

Additional file 7: Figure S7. TSA for unfavorable functional outcome in randomized controlled trials: one-sided boundary, incidence of $58.2 \%$ in the control arm, incidence of $49.5 \%$ in the intervention arm, a of 5\%, and power of $80 \%$ were set. RIS = required information size.

Additional file 8: Figure S8. Sensitivity analysis of mortality. $\mathrm{Cl}=$ confidence interval

Additional file 9: Figure S9. Sensitivity analysis of unfavorable functional outcome. $\mathrm{Cl}=$ confidence interval

Additional file 10: Figure S10. Sensitivity analysis of pneumonia. $\mathrm{Cl}=$ confidence interval

Additional file 11: Figure S11. Bias curve between sample size and bias score. correlation coefficient $r=0.678$, coefficient of determination $\mathrm{R}^{2}=0.46 . p=0.001$

Additional file 12: Figure S12. Column chart about research centres and bias. $\mathrm{t}=2.3, p=0.032$

Additional file 13: Table S1. Modified Jadad scoring for the included RCTs $(n=22)$

Additional file 14: Table S2. The risk of bias of included RCTs

\section{Abbreviations}

RIS: Required information size; GCS: Glasgow Coma Score; GOS: Glasgow Outcome Scale; GOS-E: Glasgow Outcome Scale-Extended; ICP: Intracranial 
hypertension; TBI: Traumatic brain injury; TH: Therapeutic hypothermia; TSA: Trial sequential analysis

\section{Acknowledgements}

We are grateful to Ling Liu (Department of Critical Care Medicine, Zhongda Hospital, School of Medicine, Southeast University, Nanjing, China) for participating in the assignment of bias assessments. We would like to thank the authors of the studies that were included in this analysis. Their work is very much appreciated.

\section{Authors' contributions}

$\mathrm{HC}$ designed the study, searched the scientific literature, collected the data, performed statistical analyses and drafted the manuscript. FW searched the scientific literature, collected the data and performed statistical analyses. PY contributed to the conception, data interpretation and quality assessment of the study. JS collected the data, resolved differences and performed statistical analyses. QC participated in the design, resolved differences, helped to revise the manuscript and provided technical or material support. RZ helped to revise the manuscript and provided administrative, technical or material support. All authors have read and approved the final manuscript.

\section{Funding}

Contract grant sponsor: National Natural Science Foundations of China; contract grant number 81670067 .

Social Development Funds of Jiangsu Province; contract grant number BE2017691.

Social Development Funds of Yangzhou City (No.YZ2017086).

\section{Availability of data and materials}

All data generated or analysed during this study are included in this published article.

\section{Ethics approval and consent to participate}

Not applicable.

\section{Consent for publication}

All authors have agreed to the publication of this manuscript.

\section{Competing interests}

The authors declare that they have no competing interests.

\section{Author details}

${ }^{1}$ Graduate School of Dalian Medical University; Department of Critical Care Medicine, Northern Jiangsu People's Hospital; Clinical Medical College, Yangzhou University, No.98 Nantong West Road, Yangzhou 225001, Jiangsu, China. ${ }^{2}$ Department of Intensive Care Unit, Affiliated Hospital of Yangzhou University, Clinical Medical College, Yangzhou University, No.368 Hanjiangzhonglu Road, Yangzhou 225001, Jiangsu, China. ${ }^{3}$ Department of Critical Care Medicine, Northern Jiangsu People's Hospital; Clinical Medical College, Yangzhou University, No.98 Nantong West Road, Yangzhou 225001, Jiangsu, China. ${ }^{4}$ Department of Critical Care Medicine, Jiangdu People's Hospital of Yangzhou, Jiangdu People's Hospital Affiliated to Medical College of Yangzhou University, No 9 Dongfanghong Road of Jiangdu District, Yangzhou 225001, Jiangsu, China.

Received: 30 June 2019 Accepted: 12 November 2019 Published online: 05 December 2019

\section{References}

1. Maas AIR, Menon DK, Adelson PD, Andelic N, Bell MJ, Belli A, Bragge P, Brazinova A, Buki A, Chesnut RM, et al. Traumatic brain injury: integrated approaches to improve prevention, clinical care, and research. Lancet Neurol. 2017;16(12):987-1048. https://doi.org/10.1016/ s1474-4422(17)30371-x.

2. Andrews PJD, Sinclair HL, Rodriguez A, Harris BA, Battison CG, Rhodes JKJ, Murray GD. Hypothermia for intracranial hypertension after traumatic brain injury. N Engl J Med. 2015;373(25):2403-12. https://doi.org/10.1056/ NEJMoa1507581.

3. Cooper DJ, Nichol A, Presneill J. Hypothermia for intracranial hypertension after traumatic brain injury. N Engl J Med. 2016;374(14):1384. https://doi.org/ 10.1056/NEJMc1600339.
4. Bergman KS, Beekmans V, Stromswold J. Considerations for neuroprotection in the traumatic brain injury population. Crit Care Nurs Clin North Am. 2015. 27(2):225.

5. Dietrich WD, Bramlett HM. The evidence for hypothermia as a Neuroprotectant in traumatic brain injury. Neurother. 2010;7(1):43-50.

6. Zhao QJ, Zhang XG, Wang LX. Mild hypothermia therapy reduces blood glucose and lactate and improves neurologic outcomes in patients with severe traumatic brain injury. J Crit Care. 2011;26(3):311-5. https://doi.org/10. 1016/j.jcrc.2010.08.014.

7. Gal R, Cundrle I, Zimova I, Smrcka M. Mild hypothermia therapy for patients with severe brain injury. Clin Neurol Neurosurg. 2002;104(4):318-21.

8. Cooper DJ, Nichol AD, Bailey M, Bernard S, Cameron PA, Pili-Floury S, Forbes A, Gantner D, Higgins AM, Huet O, et al. Effect of early sustained prophylactic hypothermia on neurologic outcomes among patients with severe traumatic brain injury: the POLAR randomized clinical trial. JAMA. 2018;320(21):2211-20. https://doi.org/10.1001/jama.2018.17075.

9. Andrews PJD, Rodriguez A, Suter P, Battison CG, Rhodes JKJ, Puddu I, Harris BA. Mortality risk stratification after traumatic brain injury and hazard of death with titrated hypothermia in the Eurotherm3235Trial. Crit Care Med. 2017:45(5):883-90. https://doi.org/10.1097/ccm.0000000000002376.

10. Crossley S, Reid J, McLatchie R, Hayton J, Clark C, MacDougall M, Andrews PJ. A systematic review of therapeutic hypothermia for adult patients following traumatic brain injury. Crit Care. 2014;18(2):R75. https://doi.org/10.1186/cc13835.

11. Zhu Y, Yin H, Zhang R, Ye X, Wei J. Therapeutic hypothermia versus normothermia in adult patients with traumatic brain injury: a meta-analysis. SpringerPlus. 2016;5(1):801. https://doi.org/10.1186/s40064-016-2391-2.

12. Crompton EM, Lubomirova I, Cotlarciuc I, Han TS, Sharma SD, Sharma P. Meta-analysis of therapeutic hypothermia for traumatic brain injury in adult and pediatric patients. Crit Care Med. 2017;45(4):575-83. https://doi.org/10. 1097/ccm.0000000000002205.

13. Watson HI, Shepherd AA, Rhodes JKJ, Andrews PJD. Revisited: a systematic review of therapeutic hypothermia for adult patients following traumatic brain injury. Crit Care Med. 2018;46(6):972-9. https://doi.org/10.1097/ccm. 0000000000003125.

14. Moher D, Liberati A, Tetzlaff J, Altman DG. Preferred reporting items for systematic reviews and meta-analyses: the PRISMA statement. BMJ. 2009; 339:b2535. https://doi.org/10.1136/bmj.b2535.

15. Clifton GL, Allen S, Barrodale P, Plenger P, Berry J, Koch S, Fletcher J, Hayes RL, Choi SC. A phase II study of moderate hypothermia in severe brain injury. J Neurotrauma. 1993;10(3):263-71; discussion 273. https://doi.org/10. 1089/neu.1993.10.263

16. Shiozaki T, Sugimoto $H$, Taneda M, Yoshida $H$, Iwai A, Yoshioka T, Sugimoto T. Effect of mild hypothermia on uncontrollable intracranial hypertension after severe head injury. J Neurosurg. 1993;79(3):363-8. https://doi.org/10. 3171/jns.1993.79.3.0363.

17. Marion DW, Penrod LE, Kelsey SF, Obrist WD, Kochanek PM, Palmer AM, Wisniewski SR, DeKosky ST. Treatment of traumatic brain injury with moderate hypothermia. N Engl J Med. 1997;336(8):540-6. https://doi.org/10. 1056/NEJM199702203360803.

18. Shiozaki T, Kato A, Taneda M, Hayakata T, Hashiguchi N, Tanaka H, Shimazu T, Sugimoto H. Little benefit from mild hypothermia therapy for severely head injured patients with low intracranial pressure. J Neurosurg. 1999;91(2): 185-91. https://doi.org/10.3171/jns.1999.91.2.0185.

19. Aibiki M, Maekawa S, Yokono S. Moderate hypothermia improves imbalances of thromboxane A2 and prostaglandin 12 production after traumatic brain injury in humans. Crit Care Med. 2000;28(12):3902-6.

20. Jiang JY, Yu MK, Zhu C. Effect of long-term mild hypothermia therapy in patients with severe traumatic brain injury: 1-year follow-up review of 87 cases. J Neurosurg. 2000;93(4):546-9.

21. Clifton GL, Miller ER, Choi SC, Levin HS, McCauley S, Smith KR Jr, Muizelaar JP, Wagner FC Jr, Marion DW, Luerssen TG, et al. Lack of effect of induction of hypothermia after acute brain injury. N Engl J Med. 2001;344(8):556-63. https://doi.org/10.1056/nejm200102223440803.

22. Shiozaki T, Hayakata T, Taneda M, Nakajima Y, Hashiguchi N, Fujimi S, Nakamori Y, Tanaka H, Shimazu T, Sugimoto H. A multicenter prospective randomized controlled trial of the efficacy of mild hypothermia for severely head injured patients with low intracranial pressure. Mild Hypothermia Study Group in Japan. J Neurosurg. 2001;94(1):50-4. https://doi.org/10.3171/ jns.2001.94.1.0050

23. Hashiguchi N, Shiozaki T, Ogura H, Tanaka H, Koh T, Noborio M, Fugita K, Akimau P, Kuwagata Y, Shimazu T, et al. Mild hypothermia reduces 
expression of heat shock protein 60 in leukocytes from severely headinjured patients. J Trauma. 2003;55(6):1054-60. https://doi.org/10.1097/01.ta. 0000033252.43742.8b.

24. Meissner W, Krapp C, Kauf E, Dohrn B, Reinhart K. Thyroid hormone response to moderate hypothermia in severe brain injury. Intensive Care Med. 2003;29(1):44-8. https://doi.org/10.1007/s00134-002-1556-3.

25. Zhi D, Zhang S, Lin X. Study on therapeutic mechanism and clinical effect of mild hypothermia in patients with severe head injury. Surg Neurol. 2003; 59(5):381-5

26. Qiu WS, Liu WG, Shen H, Wang WM, Hang ZL, Zhang Y, Jiang SJ, Yang XF. Therapeutic effect of mild hypothermia on severe traumatic head injury. Chinese J Traumatol. 2005;8(1):27-32.

27. Smrcka M, Vidlak M, Maca K, Smrcka V, Gal R. The influence of mild hypothermia on ICP, CPP and outcome in patients with primary and secondary brain injury. Acta Neurochir Suppl. 2005;95:273-5.

28. Liu WG, Qiu WS, Zhang Y, Wang WM, Lu F, Yang XF. Effects of selective brain cooling in patients with severe traumatic brain injury: a preliminary study. J Int Med Res. 2006;34(1):58-64. https://doi.org/10.1177/ 147323000603400107.

29. Qiu W, Zhang Y, Sheng H, Zhang J, Wang W, Liu W, Chen K, Zhou J, Xu Z. Effects of therapeutic mild hypothermia on patients with severe traumatic brain injury after craniotomy. J Crit Care. 2007;22(3):229-35. https://doi.org/ 10.1016/j.jcrc.2006.06.011.

30. Harris OA, Muh CR, Surles MC, Pan Y, Rozycki G, Macleod J, Easley K. Discrete cerebral hypothermia in the management of traumatic brain injury: a randomized controlled trial. J Neurosurg. 2009;110(6):1256-64. https://doi. org/10.3171/2009.1.jns081320.

31. Clifton GL, Valadka A, Zygun D, Coffey CS, Drever P, Fourwinds S, Janis LS, Wilde E, Taylor P, Harshman K, et al. Very early hypothermia induction in patients with severe brain injury (the National Acute Brain Injury Study: Hypothermia II): a randomised trial. Lancet Neurol. 2011;10(2):131-9. https:// doi.org/10.1016/s1474-4422(10)70300-8

32. Maekawa T, Yamashita S, Nagao S, Hayashi N, Ohashi Y. Prolonged mild therapeutic hypothermia versus fever control with tight hemodynamic monitoring and slow rewarming in patients with severe traumatic brain injury: a randomized controlled trial. J Neurotrauma. 2015;32(7):422-9. https://doi.org/10.1089/neu.2013.3197.

33. Tang C, Bao Y, Qi M, Zhou L, Liu F, Mao J, Lei Q, Qi S, Qiu B. Mild induced hypothermia for patients with severe traumatic brain injury after decompressive craniectomy. J Crit Care. 2017;39:267-70. https://doi.org/10. 1016/j.jcrc.2016.12.012.

34. Idris Z, Zenian MS, Muzaimi M, Hamid WZ. Better Glasgow outcome score, cerebral perfusion pressure and focal brain oxygenation in severely traumatized brain following direct regional brain hypothermia therapy: a prospective randomized study. Asian J Neurosurg. 2014;9(3):115-23. https:// doi.org/10.4103/1793-5482.142690.

35. Peterson $\mathrm{K}$, Carson S, Carney N. Hypothermia treatment for traumatic brain injury: a systematic review and meta-analysis. J Neurotrauma. 2008;25(1):62-71.

36. De Rosa S, De Cal M, Joannidis M, Villa G, Pacheco JLS, Virzi GM, Samoni S, D'Ippoliti F, Marcante S, Visconti F, et al. The effect of whole-body cooling on renal function in post-cardiac arrest patients. BMC Nephrol. 2017;18(1): 376. https://doi.org/10.1186/s12882-017-0780-6.

37. Jiang JY, Gao GY, Li WP, Yu MK, Zhu C. Early indicators of prognosis in 846 cases of severe traumatic brain injury. J Neurotrauma. 2002;19(7):869-74. https://doi.org/10.1089/08977150260190456.

38. Kelts EA. Traumatic brain injury and visual dysfunction: a limited overview. NeuroRehabilitation. 2010;27(3):223-9. https://doi.org/10.3233/ nre-2010-0601.

39. Polderman $\mathrm{KH}$. Application of therapeutic hypothermia in the ICU: opportunities and pitfalls of a promising treatment modality. Part 1 : indications and evidence. Intensive Care Med. 2004;30(4):556-75. https://doi. org/10.1007/s00134-003-2152-x.

40. Marion DW, Obrist WD, Carlier PM, Penrod LE, Darby JM. The use of moderate therapeutic hypothermia for patients with severe head injuries: a preliminary report. J Neurosurg. 1993;79(3):354-62. https://doi.org/10.3171/ jns.1993.79.3.0354.

41. Lyeth BG, Jiang JY, Liu S. Behavioral protection by moderate hypothermia initiated after experimental traumatic brain injury. J Neurotrauma. 1993; 10(1):57-64. https://doi.org/10.1089/neu.1993.10.57.

42. Carney N, Totten AM, O'Reilly C, Ullman JS, Hawryluk GW, Bell MJ, Bratton SL, Chesnut R, Harris OA, Kissoon N, et al. Guidelines for the management of severe traumatic brain injury, Fourth Edition. Neurosurgery. 2017;80(1):615. https://doi.org/10.1227/neu.0000000000001432.

43. Polderman $\mathrm{KH}$. Mechanisms of action, physiological effects, and complications of hypothermia. Crit Care Med. 2009;37(7 Suppl):S186-202. https://doi.org/10.1097/CCM.0b013e3181aa5241.

44. Sahuquillo J, Vilalta A. Cooling the injured brain: how does moderate hypothermia influence the pathophysiology of traumatic brain injury. Curr Pharm Des. 2007;13(22):2310-22.

45. Geurts M, Macleod MR, Kollmar R, Kremer PHC, van der Worp HB. Therapeutic hypothermia and the risk of infection: a systematic review and meta-analysis. Crit Care Med. 2014;42(2):231-42.

46. Dengler B, Garvin R, Seifi A. Can therapeutic hypothermia trigger propofolrelated infusion syndrome? J Crit Care. 2015;30(4):823-4. https://doi.org/10. 1016/j.jcrc.2015.03.027

47. Heier T, Caldwell JE. Impact of hypothermia on the response to neuromuscular blocking drugs. Anesthesiology. 2006;104(5):1070-80. https:// doi.org/10.1097/00000542-200605000-00025.

48. Roberts I, Yates D, Sandercock P, Farrell B, Wasserberg J, Lomas G, Cottingham R, Svoboda P, Brayley N, Mazairac G, et al. Effect of intravenous corticosteroids on death within 14 days in 10008 adults with clinically significant head injury (MRC CRASH trial): randomised placebo-controlled trial. Lancet. 2004;364(9442):1321-8. https://doi.org/10.1016/s01406736(04)17188-2.

49. Kim Y, Busto R, Dietrich WD, Kraydieh S, Ginsberg MD. Delayed postischemic hyperthermia in awake rats worsens the histopathological outcome of transient focal cerebral ischemia. Stroke. 1996;27(12):2274-80; discussion 2281. https://doi.org/10.1161/01.str.27.12.2274.

50. Baena RC, Busto R, Dietrich WD, Globus MY, Ginsberg MD. Hyperthermia delayed by 24 hours aggravates neuronal damage in rat hippocampus following global ischemia. Neurology. 1997;48(3):768-73. https://doi.org/10. 1212/wnl.48.3.768.

51. Lotocki G, de Rivero Vaccari JP, Perez ER, Alonso OF, Curbelo K, Keane RW, Dietrich WD. Therapeutic hypothermia modulates TNFR1 signaling in the traumatized brain via early transient activation of the JNK pathway and suppression of XIAP cleavage. Eur J Neurosci. 2006;24(8):2283-90. https:// doi.org/10.1111/j.1460-9568.2006.05123.x.

52. Scerrati A, De Rosa S, Mongardi L, Cavallo MA, Trapella G, De Bonis P. Standard of care, controversies, and innovations in the medical treatment of severe traumatic brain injury. J Neurosurg Sci. 2018;62(5):574-83. https://doi. org/10.23736/s0390-5616.18.04462-4.

53. Burger R, Bendszus M, Vince GH, Solymosi L, Roosen K. Neurophysiological monitoring, magnetic resonance imaging, and histological assays confirm the beneficial effects of moderate hypothermia after epidural focal mass lesion development in rodents. Neurosurgery. 2004;54(3):701-11; discussion 711-702. https://doi.org/10.1227/01.neu.0000108784.80585.ee.

\section{Publisher's Note}

Springer Nature remains neutral with regard to jurisdictional claims in published maps and institutional affiliations. 